\title{
Evaluation of the Changes of Salivary pH among Dental Students Depending on Their Anxiety Level
}

\author{
Olga Bait Said ${ }^{1}$ Svetlana Razumova ${ }^{1} \quad$ Ellina Velichko ${ }^{1}$ Svetlana Tikhonova ${ }^{1}$ Haydar Barakat ${ }^{1}$ \\ 1Department of Propaedeutic of Dental Diseases, Peoples' \\ Friendship University of Russia (RUDN University), Moscow, Russia \\ Address for correspondence Olga Bait Said, Department of \\ Propaedeutic of Dental Diseases, Peoples' Friendship University \\ of Russia (RUDN University), 117198, 6. Miklukha Maklaya, \\ Moscow, Russia (e-mail: milk10milk@hotmail.com).
}

Eur J Dent:2020;14:605-612

\begin{abstract}
Keywords

- anxiety

- dental phobia

- oral fluid

- $\mathrm{pH}$ changes

- stress
\end{abstract}

Objectives The aim of this study was to determine the correlation between the state of anxiety (S-anxiety and T-anxiety based on the state-trait anxiety inventory [STAI] test) and the manifestation of dentophobia with changes in salivary $\mathrm{pH}$.

Materials and Methods The data of 105 patients, aged 18 to 23 were considered. The student's anxiety levels were evaluated by the STAI test and they were distributed into three groups. To determine dental anxiety, Corah's dental anxiety scale (CDAS) testing was performed. To determine the changes in salivary $\mathrm{pH}$, samples were obtained, and $\mathrm{pH}$ level of the collected whole saliva was evaluated immediately using pHSCAN 5.4-10.0 litmus paper and a scale in 0.1 to 0.4 increments. Statistical significance was set at 0.05 .

Results Group I experienced a low level of anxiety and included 33 students (31.4\%). Group II comprised of 32 (30.5\%) students presenting with a moderate level of anxiety. In group III, 40 students (38.1\%) were having a high level of anxiety. Out of the 105 participants, $85 \%$ of students showed low level of dentophobia, $27 \%$ of them showed a low level of anxiety, $29 \%$ showed moderate level of anxiety, and $28 \%$ showed high level of anxiety. The average salivary $\mathrm{pH}$ value among all the participants (105 students) at rest was 6.79 and in a state of anxiety 6.43 .

Conclusion within the limits of this study, a correlation was found between the anxiety level and the salivary $\mathrm{pH}$ level. Furthermore, a change in the salivary $\mathrm{pH}$ toward acidity was registered in each group of students when in a stressful situation.

\section{Introduction}

The modern life of patients seeking dental care is filled with large amount of information flow and external stress stimuli, which are nearly impossible to avoid. The phenomenon of stress, defined as a scientific concept by Hans Selye (stress: the nonspecific response of the body to any demand for change), has long extended beyond psychology as a science into related fields of biology, physiology, and medicine. ${ }^{1}$ This extension was caused by an increase in the number of stress-related situations associated with urbanization, increased information flow, acceleration in life pace, increased number of interpersonal interactions, as well as the development of discordance between the human biology

DOI https://doi.org/

$10.1055 / \mathrm{s}-0040-1714758$

ISSN 1305-7456. and the conditions of social existence. In recent years, the number of physical pathologies caused by a psychoemotional overload in people has drastically increased. ${ }^{2}$

The studies on psychological manifestations of overstrain associated with exposure to excessive stress have shown to be related to gender and both somatic, emotional, and behavioral symptoms have been singularized. ${ }^{3}$ One of the manifestations of emotional symptoms is anxiety. The methodology applied to study the psychological phenomenon of anxiety is the Spielberger-Hanin test (state-trait anxiety inventory [STAI]). ${ }^{4}$ This test allows to evaluate the level of anxiety of people aged over 16 years, those who experience anxiety in a specific situation (reactive anxiety as a state, S-Anxiety $[\mathrm{SA}])$ and those who generally experience it, trait anxiety, 
(as a persisting personality trait, T-anxiety [TA]). Since the middle of the 20th century, scientists working in various fields of medicine, including dentistry, have been actively researching the effects of stress on the human body and developing strategies for its counteraction through the introduction of preventive and stress correcting methods. ${ }^{5}$ To measure dentophobia the Corah dental anxiety scale (CDAS) test is used. This scale consists of four questions and evaluates the intensity of a patient's dental phobia during a dentist's appointment. High emotional tension (dentophobia) reduces the efficiency of provided treatment, makes it untimely, which in turn leads to the decrease in oral health. ${ }^{6}$ Dentophobia can manifest itself at a young age and follow the individual throughout life into adulthood. The questions on how to diagnose patient anxiety (including dentophobia) and which methods to use for detecting anxiety-related changes in the oral cavity remain unsolved.

Human saliva is a vital fluid found in the oral cavity and has a role in maintaining human health, in addition to its role in detecting oral diseases and other disorders. Human saliva contains various mixtures of proteins, peptides, DNA, miRNA, exosomes, and electrolytes that can help diagnose diseases. ${ }^{7}$ Recently, point-of-care technology was presented to detect the absence or presence of diseases in human fluids that demonstrates the role of saliva in the investigation of diseases. ${ }^{8}$ Salivary secretion is regulated by a reflex arc that consists of afferent receptors and nerves carrying impulses that are induced by the actions of gustation and mastication, salivation center, and an efferent part that consists of parasympathetic and sympathetic autonomic nerves. ${ }^{9}$ Therefore, the secretion of saliva, as well as its composition and functions, are controlled by the sympathetic and parasympathetic autonomic nervous systems. ${ }^{9}$ Korot'ko et al, ${ }^{10}$ Komarova LG, ${ }^{11}$ Vinogradov SYu, and other scientists led studies on stress-related changes in the properties of saliva as well as on the anxiety to salivation ratio. ${ }^{13-15}$ Increased acidity levels in saliva are registered when in a state of anxiety. ${ }^{14}$ During stress, fear, and anxiety, the secretion of saliva decreases, and the concentration of hydrogen ions $(\mathrm{pH})$ enhances its acidity. ${ }^{16,17}$ Changes in salivary $\mathrm{pH}$ are closely related to the caries resistance properties of saliva ${ }^{18}$ and therefore used to evaluate the intensity of tooth decay.

In patients seeking dental care, it is extremely important to consider such indicators as: stress resistance, the level of anxiety, and dentophobia, the diagnostic criteria by which these factors are evaluated, the choice of treatment, applied materials, and the methods used to correct the changes in salivary $\mathrm{pH}$ caused by anxiety and dentophobia, as they allow to improve the quality of dental care. The aim of this study was to determine the correlation between the state of anxiety (SA and TA based on the STAI test) and the manifestation of dentophobia (using CDAS) with changes in salivary $\mathrm{pH}$.

\section{Materials and Methods}

Clinical studies were performed at Department of Propaedeutic of Dental Diseases and the study was conducted in accordance with the Helsinki Declaration of 1975, as revised in 2000, and was approved by the Ethical Committee of the Peoples' Friendship University of Russia (protocol 9 at May 23, 2019). Prior to the study, all the patients were informed about its purpose and procedures and a written consent was obtained from all the participants. A total of 180 students were examined. Data on 75 patients were excluded due to incomplete testing.

The exclusion criteria were as followed: being on medication, pregnancy at the time of the study, patients belonging to the 3rd or 4th health status groups, that is, individuals with chronic infectious and noninfectious diseases, being younger than 18 or older than 23 years and patients who have not completed all the necessary examinations and tests.

For a complete analysis, the data of 105 dental students of the first and second years, aged 18 to 23 years were taken into account. The student's anxiety levels were evaluated by the STAI test and they were subsequently distributed into groups; group I experienced a low level of anxiety, group II presenting a moderate level of anxiety, and group III with a high level of anxiety.

To determine dental anxiety, CDAS testing was performed. This scale includes four questions which determine the level of a patient's dentophobia during a dentist's appointment.

Clinical examination methods were performed according to the research protocol using standard methodology and the necessary disposable sets of dental instruments.

To determine the changes in salivary $\mathrm{pH}$, samples were obtained using the following method: the patients rinsed their mouths with $50 \mathrm{~mL}$ of distilled water, then their whole saliva was collected in sterile tubes for 3 minutes by having the participants actively collecting the fluid and depositing it into the tubes. The $\mathrm{pH}$ level of the collected whole saliva was evaluated immediately upon collection using pHSCAN 5.4-10.0 litmus paper and a scale in 0.1 to 0.4 increments. The litmus paper was immersed into the test tube containing the collected saliva for 1 to 2 seconds and after 5 seconds applied to the scale designed as a color table to determine the salivary pH level. Since the state of anxiety needed to be created without causing any traumatic experience for the students, the decision was made to evaluate their salivary $\mathrm{pH}$ level during an exam. The tests were performed during a 15-minute time span starting from the moment a student received their exam question till the end of the preparatory time, which in terms of human physiology marks the peak of anxiety and corresponds to the decay of catecholamines released into the bloodstream under the influence of monoamine oxidases. ${ }^{19}$

For statistical analysis, values were entered into a database and the SPSS statistical package v22.0 was used for analyzing data. For the descriptive analysis of quantitative variables, dispersion measures (mean, standard deviation, and variance) were used. For comparison between groups an independent $t$-test was used. Statistical significance was set at 0.05 .

\section{Results}

This study included 105 dental students, 54 of whom were male (51.43\%) and 51 females (48.57\%) (-Table 1). 
The student's anxiety levels were evaluated by the STAI test and in accordance to its results the subjects were divided into three groups.

Group I experienced a low level of anxiety and included 33 students (31.4\%). The distribution by gender was as follows: 15 males (27.87\%) and 18 females (35.3\%). The amount of points registered for each of the SA and TA test forms did not exceed 30.

Group II comprised of 32 (30.5\%) students presenting with a moderate level of anxiety, 27 of whom were male (50\%) and 5 were female (9.8\%). The amounted points for each of the SA and TA test forms remained within the range of 31 to 45.

Group III consisted of 40 students (38.1\%), having a high level of anxiety. Twelve of whom were male (22.22\%) and $28(54.9 \%)$ were female. The amount of points for each of the SA and TA test forms was within the range of 46 to 60 (-Table 2).

The following data were obtained in the CDAS study of dental anxiety:

Table 1 Quantitative distribution of the participants by gender

\begin{tabular}{|l|l|l|}
\hline \multicolumn{3}{|l|}{ Number of students $(n)=105$ people } \\
\hline $\begin{array}{l}\text { Comparison } \\
\text { criteria }\end{array}$ & Male students & Female students \\
\hline $\begin{array}{l}\text { Number of } \\
\text { students }\end{array}$ & $54(100 \%)$ & $51(100 \%)$ \\
\hline Average age & $18.82 \pm 1.45$ & $19.70 \pm 1.37$ \\
\hline
\end{tabular}

Table 2 Evaluation of the state anxiety and trait anxiety results according to STAI

\begin{tabular}{|l|c|}
\hline $\begin{array}{l}\text { Total number of students evaluated using } \\
\text { STAI (SA and TA) }\end{array}$ & 105 (100\%) \\
\hline $\begin{array}{l}\text { Number of students with low levels of SA and } \\
\text { TA evaluated using STAI }\end{array}$ & $33(31.42 \%)$ \\
\hline $\begin{array}{l}\text { Number of students with mid-level of SA and } \\
\text { TA evaluated using STAI }\end{array}$ & $32(30.47 \%)$ \\
\hline $\begin{array}{l}\text { Number of students with high levels of SA and } \\
\text { TA evaluated using STAI }\end{array}$ & $40(38.09 \%)$ \\
\hline
\end{tabular}

Abbreviations: SA, STAI, state-trait anxiety inventory; state anxiety; TA, trait anxiety.
Out of the 105 participants (100\%), 90 students (85.71\%) were registered with a low level of dentophobia. Twentynine $(27.62 \%)$ of these students evaluated using STAI showed a low level of anxiety (SA and TA), 31 (29.52\%) presented with a moderate level of anxiety, and 30 (28.57\%) with a high level of anxiety (-Table 3 ).

A moderate level of dentophobia (by CDAS) was observed in $15(14.28 \%)$ students out of the total $105.4(3.81 \%)$ of these 15 students showed a low level of anxiety (ST and TA), 4 (3.81\%) showed a moderate level of anxiety and 7 (6.67\%) showed a high anxiety level evaluated using STAI ( - Table 3 ). None of the students enrolled in the clinical study showed high levels of dentophobia evaluated with CDAS. Possibly due to the fact that the examined patients are dental students who are less psychoemotionally dispositioned to fearing dental treatment. These indicators may therefore differ among students of other specialties. Subsequently, an evaluation of the state of health of the oral cavity was performed. This included a collection of the student's medical history (anamnesis), as well as the registration of any given complaints, an external examination of the maxillofacial region and the measurement of the oral fluid $\mathrm{pH}$, which was performed twice: at rest and in a state of anxiety. The obtained $\mathrm{pH}$ results of the recovered saliva are shown in - Table 4.

The average salivary $\mathrm{pH}$ value among all the participants (105 students) at rest was $6.79 \pm 0.48$ and in a state of anxiety was $6.43 \pm 0.62$. In group I, this value at rest measured $6.71 \pm 0.50$, and $6.66 \pm 0.68$ in a state of anxiety. In group II, the average salivary $\mathrm{pH}$ at rest was $6.89 \pm 0.40$, and $6.39 \pm 0.50$ in a state of anxiety. In group III, the whole saliva $\mathrm{pH}$ at rest measured $6.78 \pm 0.51$, and $6.27 \pm 0.62$ in a state of anxiety (-Fig. 1 ).

No statistically significant difference between the groups at rest was found $(p>0.05)$. However, when assessing the $p$-value in the anxiety groups the difference was statistically significant $(p=0.02)$. The range of salivary $\mathrm{pH}$ value fluctuations among all the examined patients $(\mathrm{pH}$ value at rest subtracted the $\mathrm{pH}$ value when in a state of anxiety) measured 0.36 . The equivalent $\mathrm{pH}$ fluctuation range in group $\mathrm{I}$ did not exceed 0.05 , in group II, it was 0.5 , and in group III, it was 0.51 .

Table 3 Evaluation of dentophobia using CDAS in students with different state anxiety and trait anxiety levels according to STAI

\begin{tabular}{|l|l|l|l|l|}
\hline $\begin{array}{l}\text { Number of } \begin{array}{l}\text { students } \\
(n=105) 100 \%\end{array} \\
\text { to CDAS }\end{array}$ & $\begin{array}{l}\text { Dentophobia level according } \\
\text { t }\end{array}$ & $\begin{array}{l}\text { Group I } \\
\text { Low-anxiety level } \\
(n=33) \\
(31.4 \%)\end{array}$ & $\begin{array}{l}\text { Group II } \\
\text { Medium-anxiety } \\
\text { level } \\
(n=32) \\
(30.5 \%)\end{array}$ & $\begin{array}{l}\text { Group III } \\
\text { High-anxiety level } \\
(n=40) \\
(38.1 \%)\end{array}$ \\
\hline $90(85.71 \%)$ & Low level of fear & $29(27.62 \%)$ & $31(29.52 \%)$ & $30(28.57 \%)$ \\
\hline $15(14.29 \%)$ & Medium level of fear & $4(3.81 \%)$ & $4(3.81 \%)$ & $7(6.67 \%)$ \\
\hline 0 & High level of fear & 0 & 0 & 0 \\
\hline
\end{tabular}

Abbreviations: CDAS, Corah's dental anxiety scale; STAI, state-trait anxiety inventory; state anxiety; TA, trait anxiety. 
Table 4 Indicators of whole saliva $\mathrm{pH}$ measurements

\begin{tabular}{|l|l|l|l|l|l|}
\hline Comparison parameters & General & $\begin{array}{l}\text { Low-level anxiety } \\
\text { group }\end{array}$ & $\begin{array}{l}\text { Medium-level } \\
\text { anxiety group }\end{array}$ & $\begin{array}{l}\text { High-level } \\
\text { anxiety group }\end{array}$ & $\begin{array}{l}\text {-value (pH compared } \\
\text { within groups) }\end{array}$ \\
\hline Whole saliva pH at rest & $6.79 \pm 0.48$ & $6.71 \pm 0.50$ & $6.89 \pm 0.40$ & $6.78 \pm 0.51$ & 0.33 \\
\hline $\begin{array}{l}\text { Whole saliva pH at rest in } \\
\text { males }\end{array}$ & $6.83 \pm 0.44$ & $6.71 \pm 0.53$ & $6.90 \pm 0.42$ & $6.83 \pm 0.36$ & 0.40 \\
\hline $\begin{array}{l}\text { Whole saliva pH at rest in } \\
\text { females }\end{array}$ & $6.75 \pm 0.52$ & $6.50 \pm 0.59$ & $6.82 \pm 0.26$ & $6.75 \pm 0.57$ & 0.42 \\
\hline $\begin{array}{l}\text { P-value (males and females } \\
\text { salivary pH compared } \\
\text { at rest) }\end{array}$ & - & 0.67 & 0.66 & 0.96 & - \\
\hline $\begin{array}{l}\text { Whole saliva pH in an } \\
\text { anxiety state }\end{array}$ & $6.43 \pm 0.62$ & $6.66 \pm 0.68$ & $6.39 \pm 0.50$ & $6.27 \pm 0.62$ & 0.02 \\
\hline $\begin{array}{l}\text { Whole saliva pH in an } \\
\text { anxiety state in Males }\end{array}$ & $6.53 \pm 0.56$ & $6.72 \pm 0.50$ & $6.62 \pm 0.59$ & $6.37 \pm 0.47$ & 0.93 \\
\hline $\begin{array}{l}\text { Whole saliva pH in an a } \\
\text { nxiety state in Females }\end{array}$ & $6.31 \pm 0.66$ & $6.30 \pm 0.40$ & $6.88 \pm 1.11$ & $6.22 \pm 0.67$ & 0.12 \\
\hline $\begin{array}{l}\text { P-value (males and females } \\
\text { salivary pH compared in an } \\
\text { anxiety state) }\end{array}$ & 0.36 & 0.05 & 0.46 & 0.27 & \\
\hline \begin{tabular}{l} 
pH range of whole saliva \\
\hline
\end{tabular} & 0.50 & 0.5 & 0.51 & \\
\hline
\end{tabular}

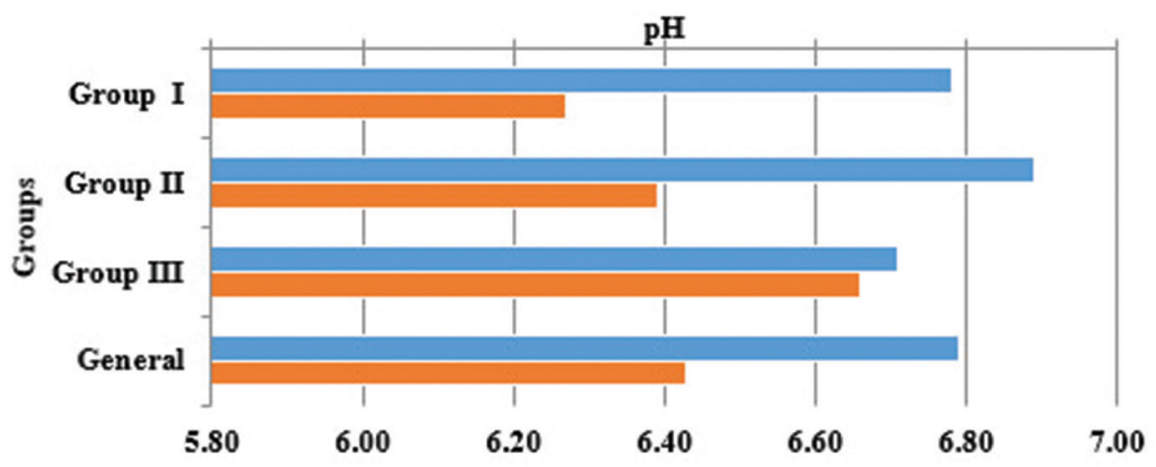

ص Whole saliva $\mathrm{pH}$ at rest

- Whole saliva in an anxiety state

Fig. 1 Comparison of whole saliva pH values among the student groups at rest and in a state of anxiety.

The majority of the oral fluid samples obtained when in an state of anxiety compared with those at rest showed a decrease in salivary $\mathrm{pH}$ toward acidity.

The average salivary $\mathrm{pH}$ value in all the examined males (54 students) at rest was $6.83 \pm 0.44$ and in a state of anxiety, it was $6.53 \pm 0.56$. Among the males in group I, the average salivary pH level at rest was $6.71 \pm 0.53$, and $6.71 \pm 0.53$ in a state of anxiety. In group II, the average value at rest measured $6.90 \pm 0.42$, and in a state of anxiety, it was $6.62 \pm 0.59$. In group III, the equivalent value measured $6.83 \pm 0.36$ at rest and $6.37 \pm 0.47$ in a state of anxiety (-Fig. 2 ). The calculated probability ( $p$-value) among the male participants in all three groups at rest was 0.40 , and 0.93 in a state of anxiety, meaning that no statistical significance between the male participants in the groups was found. The total range of salivary $\mathrm{pH}$ value fluctuations among these groups $(\mathrm{pH}$ value at rest subtracted the $\mathrm{pH}$ value when in a state of anxiety) was 0.4 . The range of the salivary $\mathrm{pH}$ value fluctuations in group
I was $0,0.28$ in group II, and 0.46 in group III. The collected saliva samples from groups II and III showed a decrease in the $\mathrm{pH}$ level toward acidity when the students were in a state of anxiety compared with when at rest.

The average salivary $\mathrm{pH}$ value measured in all the examined females (51 students) at rest was $6.75 \pm 0.52$ and $6.31 \pm 0.66$ in a state of anxiety. In group I at rest, the average $\mathrm{pH}$ value measured $6.50 \pm 0.59$, and in a state of anxiety, it was $6.30 \pm 0.40$. In group II, the average salivary $\mathrm{pH}$ at rest was $6.82 \pm 0.26$ and in an anxiety state, it was $6.88 \pm 1.11$. In group III, the equivalent $\mathrm{pH}$ value at rest measured $6.75 \pm 0.57$, and $6.22 \pm 0.67$ when in a state of anxiety. The calculated probability ( $p$-value) among the female participants in all three groups at rest was 0.42 , and 0.12 when in a state of anxiety $(p>0.05)$, meaning no statistical significance was detected (-Fig. 3). The range of salivary $\mathrm{pH}$ value fluctuations among all the examined female students ( $\mathrm{pH}$ value at rest subtracted the $\mathrm{pH}$ value when in a state of anxiety) did not exceed 0.44 . 


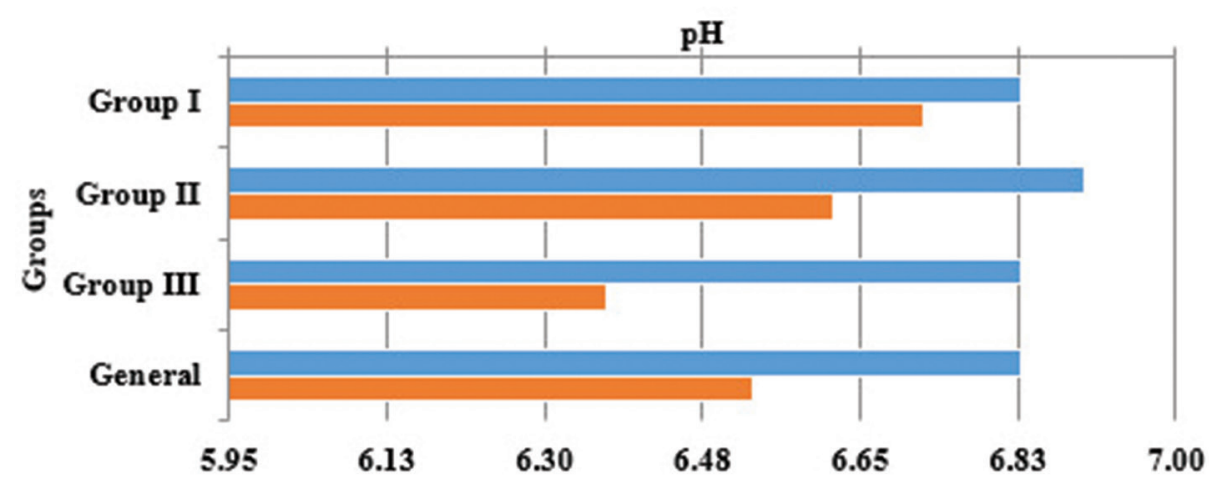

Whole saliva $\mathrm{pH}$ at rest

Whole saliva in an anxiety state

Fig. 2 Comparison of whole saliva pH values in male students at rest and in a state of anxiety.

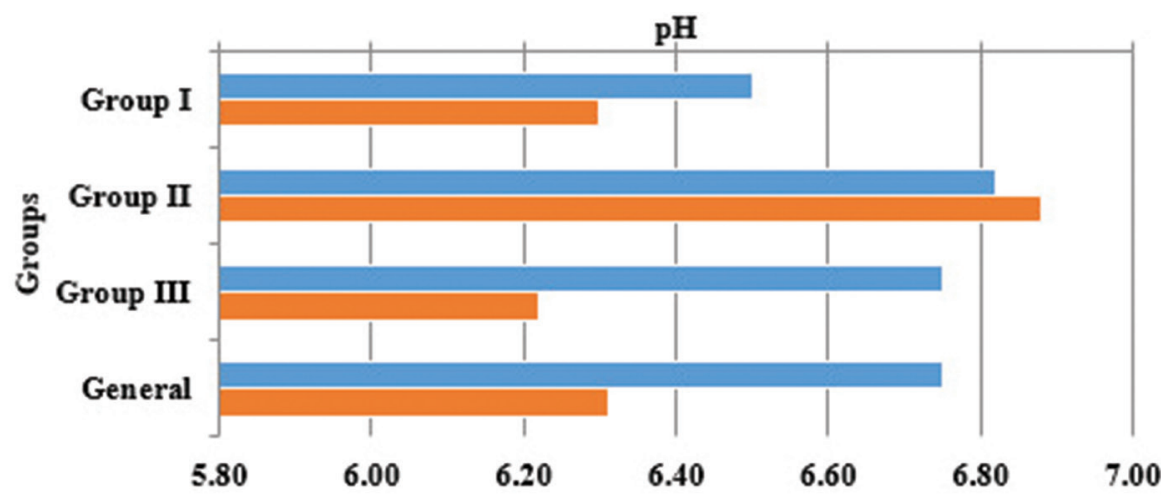

= Whole saliva $\mathrm{pH}$ at rest

- Whole saliva in an anxiety state

Fig. 3 Comparison of whole saliva pH values in female students at rest and in a state of anxiety.

The corresponding value in group I amounted to 0.2 , in group II, it was 0.06, and in group III, it was 0.53. It was discovered that a decrease in the salivary $\mathrm{pH}$ value toward acidity was observed in the collected whole saliva samples of groups I and III when the students were in a state of anxiety compared with when at rest.

The calculated probability ( $p$-value) between male and female students, at rest, was 0.67 in group I, 0.66 in group II, and 0.96 in group III. The corresponding $p$-value among male and female students, in a state of anxiety, was 0.5 in group I, 0.46 in group II, and 0.27 in group III, that is, the compared averages are not statistically significantly according to gender.

The highest range of changes is observed among female students in group III experiencing anxiety (-Fig. 4).

\section{Discussion}

Stress is a condition that affects the human system; it plays a role in the modulation of the immune response due to the reduction of the defense capacity. Because of this mechanism, the organism turns more susceptible to the development of psychosomatic and inflammatory diseases. ${ }^{20}$ This often occurs among students especially during the exam period and cold affect the oral health and cause diseases such as periodontitis and gingivitis. ${ }^{21}$ It was established that $38.09 \%$ of the students experience a high level of anxiety. The obtained results are slightly higher than those reported in the work of Saeed et al, where the percentage of students with a high anxiety level was $33.8 \%{ }^{22}$ This might be due to the difference in the ethnic background and living environment of the students in the compared studies. An analysis of the results obtained in this study among the groups based on gender revealed a prevalence of male participants. In group II (those with a moderate level of anxiety), the number of male students amounted to 27 people (50\%). The lowest number of male participants was detected in group III (high-anxiety level group) and amounted to $12(22.22 \%)$ students. These results are comparable to those obtained in the study of Petrova where the number of male participants in the group with a moderate anxiety level likewise was higher than in the groups with low and high levels of anxiety. ${ }^{23}$ The highest number of female students was detected in group III (high-anxiety level group) and totaled 


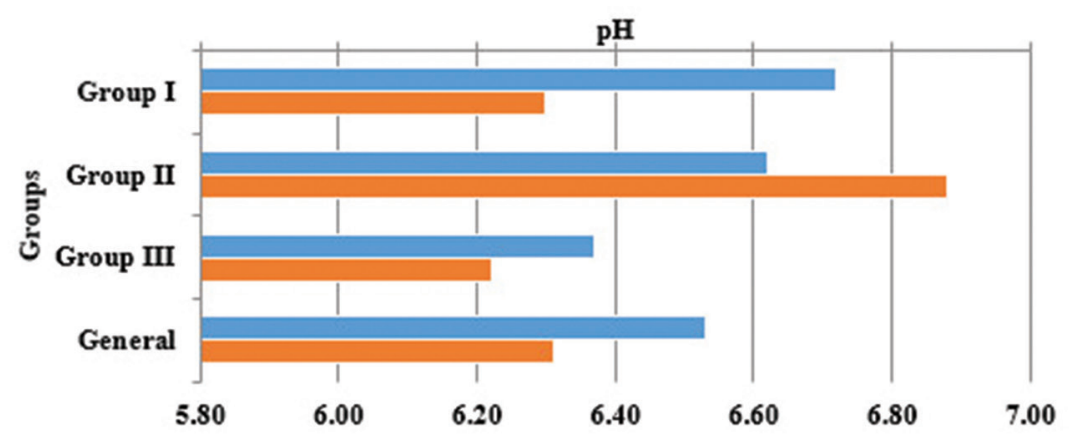

- Whole saliva pH in an anxiety state in male

- Whole saliva $\mathrm{pH}$ in an anxiety state in female

Fig. 4 Comparison of pH levels according to gender in the groups experiencing anxiety.

28 students (54.9\%), and the lowest number was observed in group II (moderate-anxiety level group) comprising a total of 5 female students (9.8\%). Thus, in group II, there were 1.8 times more males than in group I, and 2.25 times more than in group III. In regard to the female participants, there were more females in group III than in groups I and II, 1.55 and 5.6 times, respectively.

The studies of Dyrbye et al and Lozhkin showed a significant statistical difference $(p<0.05)$ between male and female students (results obtained using STAI). During the examination period, the reactive state of anxiety (SA) in females was higher than during the semester. However, this difference was not observed among the male participants. ${ }^{24,25}$ This may be due to the female gender being more prone to experiencing such events as emotional and stressful. ${ }^{26}$ In the study of Osmanovic-Thunström et al, a higher stress level was likewise observed in females (8.3\%) compared with males (5.4\%; $p=0.001) \cdot{ }^{27}$ And in the study performed by Shapovalova et al, the occurrence of stress among the participants was $28.1 \%$ in females and $11.7 \%$ in males. ${ }^{28}$ Though some studies indicate that women have higher anxiety levels, no definitive difference has been established. ${ }^{23}$ Our study did not show any statistical significance between male and female participants. According to the results of the CDAS test, 90 (85.71\%) out of 105 students involved in the study showed low levels of dentophobia, while a moderate level of dentophobia was detected in $15(14.28 \%)$ students. High levels of dentophobia were not reported. According to the study performed by Bessonov and Al-sayedi, a moderate level of dentophobia was registered in $30.6 \%$ of students ( $p>0.05$ ), and a high level of dentophobia was observed in $19.4 \%$ of the cases. No participants showed a low level of dentophobia. ${ }^{29}$ The results found in this study differ from the results of Bessonov and Al-sayedi. This is likely due to the difference in the specialties of the participating students. Those included in this research are dental students and therefore more likely to be psychoemotionally adapted to dental treatment. The study of Leonovich was dedicated to the improvement of the therapeutic dental care efficiency for children with phobic tendencies that revealed $66 \%$ out of 50 children treated under general anesthesia due to having negative or pronounced negative behavioral tendencies toward dental treatment experienced dentophobia before visiting the dentist. In the group with a pronounced negative behavioral tendency to dental procedures (103 children), dentophobia was registered in $23.3 \%$ of children. In the group with negative behavioral tendencies (101 children), a strong fear of dental treatment was detected in $52.5 \%$ of children, while high levels of anxiety were recorded in $47.5 \%$ of the examined cases. Children with a positive attitude prior to visiting the dentist did not show signs of dentophobia. However, immediately before treatment, $100 \%$ of children undergoing general anesthesia, as well as children with a distinctive negative behavioral tendency to treatment-manifested dentophobia. ${ }^{30,31}$ The fluctuations range of the obtained salivary $\mathrm{pH}$ values among all participants was 0.36 . The majority of the obtained salivary samples from the students in a state of anxiety compared with the ones obtained in a state of rest showed a decrease of the whole saliva $\mathrm{pH}$ toward acidity. Similar results were observed in the study of Kulikova et al, ${ }^{32}$ revealing a range of $\mathrm{pH}$ value fluctuations in the oral fluid of 0.62 before and after entering into a state of anxiety (prior to the development of anxiety the average salivary $\mathrm{pH}$ was 7.22 and 6.6 afterward). These changes can be a result of an increase in the motor function and secretory activity of the gastrointestinal tract upon the occurrence of an increased anxiety level (Reykovskiy ${ }^{33}$; Avramenko and Shukhtina ${ }^{34}$ ). The salivary $\mathrm{pH}$ level at rest in males with low anxiety levels was lower than in males with a moderate and high levels of anxiety measured using STAI $(p<0.05)$. The $\mathrm{pH}$ level when in the state of anxiety did not change in the group experiencing low anxiety levels but decreased in the groups with moderate and high anxiety levels, that is, an increase in salivary acidity was observed in these groups. This shows that men with a low-anxiety level is less prone to be affected by various stress stimuli. The highest whole saliva $\mathrm{pH}$ level in the female students at rest was recorded in the group with a moderate anxiety level $(6.82 \pm 0.26)$ and the lowest level in the group with a low anxiety level $(6.50 \pm 0.59)$. When exposed to a stress factor, no changes in whole saliva $\mathrm{pH}$ were detected in the group with a moderate level of anxiety, while the salivary 
$\mathrm{pH}$ decreased by 0.2 in the group with a low level of anxiety. The change in whole saliva $\mathrm{pH}$ toward acidity was more often recorded in the female group with high anxiety levels in the state of anxiety (during the exam). Most probably, the variability of salivary pH levels in females with a low stress tolerance reflects a wide range of adaptive mechanisms, which come into action at the stage of psychological discomfort due to the influence of a strong stimulus (during the exam) and activates conditioned and unconditioned reflexes which trigger protective reactions to stress.

\section{Conclusion}

The students, participating in this clinical study based on the STAI test, revealed different levels of anxiety and were distributed into three groups according to its severity: low, moderate, and high levels of anxiety. Among these groups, as well as within them a correlation was found between the anxiety level and the salivary pH level. Furthermore, a change in the salivary $\mathrm{pH}$ toward acidity was registered in each group when in a stressful situation. This in turn increases the risk of caries and its subsequent complications and lays ground for changes in recommendations and preventive measures. The identification of various stress and anxiety factors can also assist in choosing the best preventive remedies for establishing normal salivary $\mathrm{pH}$, that is, materials used and methods of carrying out dental treatment.

\section{Practical Recommendations}

Students with high anxiety levels during the examination period are recommended to consume alkaline foods, such as leafy greens and nuts, drink enough water, use oral hygiene products, use alkaline composite Cention N (Ivoclar Vivadent) when having dental caries treated, since this composite helps to neutralize oral fluid during acidosis, as it contains Calcium fluorosilicate glass (alkaline glass), which contributes to the release of $\mathrm{F} \mathrm{Ca}^{2+}$ ions and $\mathrm{OH}$, and that would help reduce the level of salivary acidity.

\section{Conflict of Interest}

None declared.

\section{References}

1 Rochette L, Vergely C. Hans Selye and the stress response: 80 years after his "letter" to the editor of nature. Ann Cardiol Angeiol (Paris) 2017;66(4):181-183

2 Yaribeygi H, Panahi Y, Sahraei H, Johnston TP, Sahebkar A. The impact of stress on body function: a review. EXCLI J 2017;16:1057-1072

3 Oyola MG, Handa RJ. Hypothalamic-pituitary-adrenal and hypothalamic-pituitary-gonadal axes: sex differences in regulation of stress responsivity. Stress 2017;20(5):476-494

4 Julian LJ. Measures of anxiety: state-trait anxiety inventory (STAI), beck anxiety inventory (BAI), and hospital anxiety and depression scale-anxiety (HADS-A) Arthritis Care Res (Hoboken) 2011;63(suppl 11) :S467-S47210.1002/acr.20561

5 Humphris GM, Morrison T, Lindsay SJ. The modified dental anxiety scale: validation and United Kingdom norms. Community Dent Health 1995;12(3):143-150
6 Savina EA, Bulkina NV, Eremin OV. Clinical approbation of the questionnaire of definition of level of dentophobiya and dynamics in the doctor-patient relationship. Sovremennye problemy nauki i obrazovaniya $2012 ; \mathrm{N}^{\circ} 3$

7 Khurshid Z, Naseem M, Sheikh Z, Najeeb S, Shahab S, Zafar MS. Oral antimicrobial peptides: types and role in the oral cavity. Saudi Pharm J 2016;24(5):515-524

8 Khurshid Z. Salivary point-of-care technology. Eur J Dent 2018;12(1):1-2

9 Humphrey SP, Williamson RT. A review of saliva: normal composition, flow, and function. J Prosthet Dent 2001; 85(2):162-169

10 Korot'ko GF, Chen NA. Ratio of psychometric parameters of quality of life and uneasiness with indicators of a salivation of the healthy person. Yuzhno-Rossiyskiy med. zhurnal. 2003; 5-6: 24-27 (in Russian).

11 Komarova LG. Salivatigiya: manograph 2006 (In Russian)

12 Vinogradov SYu, Krishtop VV, Dindyaev SV, et al. Dynamics of bioamines of a saliva as an indicator of a psychoemotiona stress at students during delivery of a concluding session. Fundamental'nye issledovaniya. 2008; 6: 112-113 (in Russian).

13 Budylina SM, Marokko IN, Raevskaia OE, Kon' II, Shilina NM. [Effect of emotionally strained activity on sensory and secretory process in the oral cavity] (in Russian) Fiziol Cheloveka 2006;32(6):129-132

14 Korot'ko GF, Salivary Gland Secretion and elements of saliva diagnostics. Moscow: Academy of Natural Sciences; 2006 164-165

15 Tarasenko LM, Sukhanova GA, Mishchenko VP, Neporada KS, Salivary Glands. Biochemistry, Physiology, Clinical Aspects. Tomsk: NTL; 2002 94-95

16 Foglio-Bonda PL, Migliario M, Rocchetti V, Pattarino F, FoglioBonda A. Daily and annually variation of unstimulated whole saliva flow rate and $\mathrm{pH}$ and their relation with body profile in healthy young adults. Eur Rev Med Pharmacol Sci 2013;17(18):2538-2545

17 Dix L, Ward DT, Stewart GS. Short communication: urea transporter protein UT-B in the bovine parotid gland. J Dairy Sci 2013;96(3):1685-1690

18 Pozharitskaya MM. The role of saliva in the physiology and development of the pathological process in hard and soft tissues of the oral cavity. Klinicheskaya Stomatologiya 2005;3:42-45 (in Russian)

19 Severin ES, Aleynikova TL, OsipovEV, SilaevaSA, Biologicheskaya khimiya. Moscow: Medical News Agency; 2008 245-246

20 Castro MM, Ferreira RO, Fagundes NCF, Almeida APCPSC, Maia LC, Lima RR. Association between psychological stress and periodontitis: a systematic review. Eur J Dent 2020;14(1):171-179

21 Ahmad FA, Alotaibi MK, Baseer MA, Shafshak SM. The effect of oral health knowledge, attitude, and practice on periodontal status among dental students. Eur J Dent 2019;13(3):437-443

22 Saeed AA, Bahnassy AA, Al-Hamdan NA, Almudhaibery FS, Alyahya AZ. Perceived stress and associated factors among medical students. J Family Community Med 2016;23(3):166-171

23 Petrova EG. Study of students' anxiety under examination stress. Bulletin of the Taganrog State Pedagogical Institute. Humanitarian Sciences 2010;2:152-157 (in Russian)

24 Lozhkin AP, Chernokhvostov YV, Dvoenosov VG, Panasyuk MV, Zhdanov RI. The influence of phychoemotional stress on white blood cells circulation and thrombodynamics in healthy volunteers. (in Russian) Kazan Medical Journal 2013;94(5):718-722

25 Dyrbye LN, Thomas MR, Huschka MM, et al. A multicenter study of burnout, depression, and quality of life in minority and nonminority US medical students. Mayo Clin Proc 2006;81(11):1435-1442

26 Tushkova KV, Bundalo NL. Reactive and personal anxiety in men and women with post-traumatic stress disorder of 
varying severity. (in Russian) Sibirskoe Meditsinskoe Obozrenie 2013;3:89-93

27 Osmanovic-Thunström A, Mossello E, Åkerstedt T, Fratiglioni L, Wang HX. Do levels of perceived stress increase with increasing age after age 65? A population-based study. Age Ageing 2015;44(5):828-834

28 Shapovalova EB, Maksimov SA, Indukaeva EV, Artamonova GV. Association of stress with cardiovascular diseases and risk factors in a population (ESSE-RF in Kemerovo region). (in Russian) Russian Journal of Cardiology 2019;24(9):7-13

29 Bessonov IP, Al-saedi YU. The incidence of dento-phobia among schoolchildren and university students. Actual problems of experimental and clinical medicine. Materials of the 76th international scientific-practical conference of young scientists and students. (in Russian). Volgograd State Medical University 2018:222-223

30 Leonovich OM. Abstract of PhD in Medical Sciences thesis. Efficiency increase of rendering therapeutic dental aid to children with phobic reactions. Minsk, Belarusian Medical State University; 2017. (in Russian)

31 Terekhova TN, Leonovich OM. Dental status in children with different level of anxiety to dental interventions. (in Russian) Experimental Psychology Of Emotions 2016;1:56-59

32 Kulikova EM, Dobrokhotov DA, Nesterova NV. The influence of phychoemotional status on the development of dental caries. Fundamental and applied research: current issues, achievements and innovations: a collection of articles from XXII International Scientific and Practical Conference. International Centre for Scientific Cooperation Nauka I Prosveschenie 2019: 239-244 (in Russian)

33 Reykovskiy Ya, Experimental Psychology of Emotions. Moscow: Progress; 1979 222-225

34 Avramenko AA, Shukhtina IN. Modern view on the mechanism of formation of symptom "heartburn" in the patients with chronic gastritis type B. Klinichna ta eksperimen- tal'na patologija 2009;4(30):3-6 